\title{
Transformation at ZABTech; an Institute of Technical and Vocational Education (iTVE)
}

\section{Page 47}

Received: 22 Oct 2020 Revised: 07 Mar 2021 Accepted: 24 Mar 2021

\section{NBR}

NUST Business Review (c) NUST Business School NBR20102201

Vol. 02 (02)

12, 2020

pp. $47-58$

DOI:

This is an open access article under the CC BY license

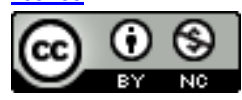

Fatima Shaikh ${ }^{a}$

a Department of Business Administration, Sukkur IBA University, Sukkur, Pakistan;

Email: Fatima.phdmgt17@iba-suk.edu.pk

Murk Memon ${ }^{b}$

${ }^{b}$ Department of Business Administration Sukkur IBA University, Sukkur, Pakistan; Email: Murk.phdmgt17@iba-suk.edu.pk

\section{Dr. Manzoor Ali Mirani ${ }^{c}$}

${ }^{c}$ Department of Business Administration Sukkur IBA University, Sukkur, Pakistan; Email:manzoor@iba-suk.edu.pk

Dr. Gul Afshan $d$

${ }^{d}$ Department of Business Administration Sukkur IBA University, Sukkur, Pakistan; Email: gul.afshan@iba-suk.edu.pk

\begin{abstract}
Subject Area of the Teaching Case.

Managing Organizational Change, A Multiple Perspective Approach $3^{\text {rd }}$ Edition Student level (e.g., BA level) and proposed courses the teaching case can be used on.
\end{abstract}

This case could be helpful to discover, build, design and sustain the change and innovation in organizations for both undergraduates and graduates' students of BBA and MBA.

Brief overview of the teaching case.

This case-based on change managing organizational change course, i.e. appreciative inquiry 4D-cycle. This case could be helpful to discover, Dream (build), design and Destiney to sustain the change and innovation in organizations for both undergraduate and graduate students in their elective course. This case can be used as a motivational story in a short seminar to bring and sustain the change effectively and efficiently.

Expected learning outcomes.

To highlight the major issues which need to be discovered or appreciation for the best of what is current practice in technical and vocational institute in developing country; such as Pakistan. Based on the available knowledge students need to envision (or dream) about what the future could be. To explore the influence of leader in designing or co-constructing (through collective dialogue) and overcome the specified issues in ZABTech (iTVE). Students should identify the actions taken by leader to sustaining the organization's destiny or future.

Keywords:

Appreciative inquiry 4D-Cycle, Case study, Managing Organizational Change, Leadership, Technical and vocational education.

Paper Type: Case Study 


\section{Opening Paragraph}

On Monday, 11th of August 2014, Ms. Mahesar, director of SZABIST-ZABTech (iTVE) had a meeting with the University's board of trustees in Karachi to revise the name of the institute. The institute's name was changed from JSTC (Job Skills Training Centre) to ZABTech (iTVE) an institute of Training and Vocational Education. She had the support of Dr Sulaiman Shaikh, a member of board of directors, who passionately promoted Ms. Mahesar as a 'positive good' and believed in her vision. She had a vision

NBR to transform a training centre to a sustainable technical and vocational institute. However, many internal and external issues were faced by Ms. Mahesar.

\section{Background of SZABIST-ZABTech (iTVE)}

ZABTech (iTVE) an institute of technical and vocational education is a sub-branch of SZABIST (Shaheed Zulfikar Ali Bhutto Institute of Science and Technology), previously, it was known as JSTC (Job Skill Training Centre). SZABIST-ZABTech (iTVE) provides technical and vocational education in the region of Sindh. ZABTech offers two types of programs; first regular programs and secondly in-source training program. The regular programs include Diploma in Information Technology (DIT), Diploma in Computer and Business Management (DCBM), Diploma in Software Engineering (DSE), Diploma in Communication Skills, Fashion Designing, Web Designing and a number of professional Certification Courses; such as International English language testing system (IELTS), Graphic designing, and computerized accounting. The time duration of DIT program is one year, the rest of the programs have a duration of six months and the duration of certification programs is threemonths. The In-source training program includes BBSYDP (Benazir Bhutto Shaheed Youth Development Program) and PMSYDP_NAVTTC (National \& Vocational Technical Training Commission) programs. In second program the service of free training programs is offered, which includes Electrician, Car driving, Motor Bike Mechanic, Photography, Tailoring \& dress making and professional Chef.

SZABIST-ZABTech is the private institute which provides technical and vocational education around the Sindh region, said by the director of ZABTech (iTVe) in her interview. There are seven well-established units /campuses of ZABTech (iTVE) in Hyderabad, Larkana, Benazir Abad, Tando Mohammad Khan, Khairpur Miras, Gharo (Thatta), and Shewan (Jamshoro). However, the focus of this research case is ZABTech (iTVE) Larkana campus (Exhibit:3). SZABIST-ZABTech (iTVE) enhances the ability and skills of individuals which provides them with a better career and the better employment opportunity, but institutes can never run on their own. Institutes always need a leader or a change manager who can build committed teams, effective communication, create motivation, to overcome internal and external resistance. This institute was facing few internal and external pressures to adapt changes. Those were creating resistance for sustainability and growth of institute. Managers or institute controls have to introduce change to improve organizational performance in terms of profitability and to achieve competitive advantage (Palmer, Dunford, \& Buchanan, 2017).

\section{Profile of Director}

Waheeda Mahesar belongs to Hyderabad's region and has done M.Sc. (Masters in Computer Science) in 2000. She has also done PGD-PA (Post Graduate Diploma in Public Administration) and MPA (Masters in Public Administration) from Sindh University Jamshoro. 
NBR

Page 49

She began her career at the age of 23 and became a Research Associate at University of Jamshoro, Sindh and then joined SZABIST university as a Computer Sciences Faculty Member. She worked as a Principal SZABIST (Shaheed Zulfikar Ali Bhutto, Institute of Science \& Technology) JSTC (Job Skill Training Centre) Benazir Abad at NawabShah from January 01, 2002 to June. 30, 2012. She had to start every activity of a job skill training centre (JSTC) from scratch. During that tenure, she faced many challenges from planning to implementation and execution, from building to purchasing equipment. It was a long and hard struggle in her professional career. For a decade, she served over there. Then she discussed with her management that she should go for other opportunities in the government sector. Management did not allow her to leave this institute and she became promoted as Manager of JSTC in 2013. She is currently working as a director (Directorate of SZABIST-ZABTech (iTVE) since April 28, 2014.

She was nominated twice and awarded by the vice-chancellor as "the best employee of the year" in 2018. She received the recognition after completing 10 years at ZABTech (iTVE). Finally, she received a letter from Vice-chancellor in which she was appreciated for all her efforts and her profile was published on Australian Global Alumni for strengthening technical and vocational training in Pakistan on 25th of May 2018 (Alumni, 2018) (Exhibit:1).

\section{Background of ZBTech (iTVE) Larkana Campus}

SZABIST-ZABTech (iTVE), 2018) an institute of technical and vocational education, previously was known as JSTC (Job Skill Training Centre) (Siyal, 2017-2018). The director renamed it because she realized the need for the change to create a competitive institute in developing countries. She was sent to Dhaka Bangladesh by the management of SZABIST for attending a workshop (TVET horizon and opportunities in Islamic Countries) in 2014 where she realized that Pakistan is far-away in the field of technical and vocational education. After coming back, she had dinner with her board of trustees for the feedback on the workshop. She discussed the possible solution for the growth of technical and vocational education, especially in Sindh.

The board of trustees firmly believed in her abilities to bring some new changes in the system of technical and vocational education for sustainability and for the growth in the field of TVET. Therefore, she took the lead to change the system from the institute's name to the operations of technical and vocational education, it was in 2014 when JSTC was renamed as ZABTech (iTVE).

\section{Significance of Technical and Vocational Education and Training (TVET)}

Technical and vocational education training (TVET) enhances the individual skill and boosts the economic growth (Kissi, Ahadzie, Debrah, \& Adjei-Kumi, 2020). TVET train the individuals for employment and makes them more productive. TVET builds individual capacity, enhance self-employment and entrepreneurship capability and help to explore the different things in an innovative way (Ansari \& $\mathrm{Wu}, 2013$; Nooruddin, 2017). TVET is a training that increases the learning capacity, knowledge, skill and attitude of individual for employment and self-earning. TVET has strong significance towards poverty reduction. However, for technical and vocational education the myriad of factors creates resistance toward the successful implementation of TVET programs, such as; funding, inadequate infrastructure, unskilled teacher, social unawareness about the significance of TVET, outdated curriculum and many more (Chamadia \& Shahid, 2018; Nwachukwu \& Yaba, 2014). 
It is highlighted in research study that technical and vocational education needs adaptation and improvement for growth and sustainability in developing countries (Kissi, et al., 2020; Shah \& Muhammad, 2017).

\section{Success Stories}

NBR

2,2

Page 50

To further analyse the practice approach of technical and vocational education, its scope and significance in interior Sindh, we also interviewed the students who have successfully incorporated their learning for lifelong benefit. Ali Hyder, a student enrolled in a BBSYDP (Benazir Bhutto Shaheed Youth Development Program), got a training of mobile repairing and he is running his own shop and earning 30,000 to 40,000 per month. Another student Mudasir Ali enrolled in regular program of DIT (Diploma in Information Technology) and successfully completed his program at SZABTech (iTVE) at Larkana campus. Presently, he has started his own small business of National Foods Distribution. He purchases the products from National Foods and maintains the whole data from purchase till sales of products and he maintains a good standard of living.

\section{Specific Issues at ZABTech (iTVE) Larkana Campus}

There were three main issues faced by ZABTech (iTVE) Larkana campus as discussed by Waheeda Mahesar during her interview (Mahesar, 2018). The first was the building and political pressure; the second was the frequent change of the Principal, and the third being slow recovery of fees from students causing a low rate of return and a decrease in financial performance.

\section{Need for Building}

The operational activities ZABTech (iTVE) was previously held at the building of the SZABIST campus. A small portion of offices and few classes were given to ZABTech (iTVE). It was not easy to run the classes of different programs in different shifts. Being the director of the institute, she wanted to increase the number of diversified technical and vocational education programs and the space of the building at the SZABIST campus was insufficient for that.

A separate building was given by the board of trustees of ZABTech (iTVE) to run all technical and vocational education activities smoothly. That building was known with the name of the community centre. The building's rent was also paid by the institute which became a financial burden for the institute. There were dual issues faced by her. First, internally to shift from SZABIST campus's building to the community centre's building and the Principal's low involvement and low interest.

The second was the external pressure from political figures, not to allow a community centre to be utilized for educational purposes. Therefore, she struggled and took some hard decisions to overcome these internal and external issues. She changed the principal and handled the external pressure from political figures by filing the case in court and the case was filed by the Board of trustees of SZABIST. The court gave the decision in favour of SZABIST-ZABTech (iTVE).

Finally, with the support of management, the operations of ZABTech (iTVE) were shifted to the community centre building and the institute was named ZABTech (iTVE) an institute of technical and vocational education. This change facilitated the director and team of Larkana campus to expand the number of programs in the field of TVET education. 


\section{Change of Principal}

For any educational institute, the Principal is an immediate decision-making authority for the betterment of the institute. Principal is a person who performs a critical role in setting goals and developing the institute (Levin \& Datnow, 2012). The work and responsibilities of the Principal remain diverse and demanding to manage the

NBR

2,2

Page 51 operations of an institute. The change of the Principal's role can affect the standards and performance of the institute (Clifford, Behrstock-Sherratt, \& Fetters, 2012). Six individuals replaced the position of Principal. It was in 2001 when Atif Kahler was appointed as first principal at JSTC; he severed JSTC for a more extended period but he faced tribal disputes in his hometown and his rival wanted to kill him. That is the reason he had to leave the job and hide in a SafePlace. Mr. Atif Kaheer belonged to a very well-educated family. However, due to a lack of education in interior Sindh, people's conservative mindset, and destructive cultural norms; if one person commits any mistake or wrongful act, the whole community of that person bears the loss. The management did not terminate him, instead he left the job due to personal issues.

The second Principal was Mr. Ghulam Mustafa Junejo; he served JSTC for a short period. He quit JSTC because he got a job at Baluchistan as an Assistant Professor. The third Principal was Mr. Nabi Bux Soomro (NB Soomro). He served JSTC for a specific period. A time came when NB Soomro was assigned a dual responsibility; as a head of a campus of SZABIST Larkana Campus and Principal of JSTC. So, the Principal's charge was taken from him and given to the fourth principal Ali Hassan Kalhoro. Mr. Ali Hassan Kalhoro, qualified English literature, was hired by the management because the institute needed a person who could handle and manage all the institute's operational activities. Still, his capabilities were not matching with the requirement of institute and he was subsequently discharged by management.

The fifth Principal was Mr. Sikandar Abbasi, who served JSTC for five years. He was found to be a lenient and flexible boss as per the staff of JSTC. It was an audit period when he was identified by the management in some wrong decisions and misutilization of assets of JSTC. When management wanted to shift from the campus building to the community centre's building, he showed low involvement and low interest in management's decision. He was resistant to adopt changes for the institute's growth and development-the reason he was discharged from the post of Principal. The sixth Principal was Ms. Gul Bano Shaikh; she was the coordinator at JSTC, working under Mr. Abbasi's supervision. Immediately, she was promoted by the management as a Principal. She served JSTC for almost three years. Under her supervision, the JSTC's operations were shifted from the SZABIST campus building to the community centre's building and named ZABTech (iTVE).

New programs and promotional campaign activities were also administrated by her as told by staff. Thus, JSTC was renamed as ZABTech (iTVE) under her working operations at Larkana campus. She resigned from the post of principal due to her marriage, her husband's job was in Karachi city and ultimately, she left the institute. Out of these six principals, three left the institute due to their personal choice or personal problems. The remaining two were delegated for a new position by higher authorities. One was asked for resignation due to low involvement and low performance for the institute's growth. Currently, Ms. Aiman Shaikh is serving at SZABTech (iTVE), and Ms. Heer Rani is working under her supervision as a Vice Principal as an immediate second command. 
The numbers of new programs such as; BBSYDP, GIZ (Deutsche Gesellschaft fur International Zusammenarbeit, Gmbh (German: German Society for International Cooperation, Ltd.) and SUCCESS (Sindh Union Council and Community Economic Strengthening Support) were also launched under the supervision of Ms. Shaikh. She is also working as a Coordinator of a new project at Kamber-Shadadkot district.

NBR

2,2

Page 52 Management of ZABTech strongly believes in internal recruitment for retaining the employee and working for their career growth. The most significant and vivid example is the director herself. Internal recruitment benefited the organization with sustainable competitive advantage (Butt, Lodhi, \& Shahzad, 2020) that is the reason management of ZABtech (iTVe) hires all Principals by promoting internal recruitment. She had been serving this organization for 17years, not only she but the people who joined at the same time are also still serving at ZABTech (iTVE). She believes in facilitating the employees and has given several internal promotions to employees for their career growth. She believes in preparing the second command; if any employee is asking for leave, she facilitates that employee because the alternate employee will handle the work on his/her behalf. She gives the flexibility to retain valuable employees and considers her employees as supporters rather than a burden.

\section{Low Rate of Return}

ZABTechiss an institute offers diploma and certification courses in the regular programs as per the need and requirement of a person. The fees of Diploma in information technology (DIT) program and Diploma in computer and Business Management (DCBM) are 22,500 PKR which can be paid by a student in the instalment of four-months. The fees structure of the programs lasting for six months is 10,600PKR which can also be paid in monthly instalments. The fees of certification courses which have duration of three-months is 7,700PKR which can also be paid in monthly instalments. Usually, students pay fees for the first or second instalment then leave the course due to lack of interest or less awareness about the importance of those courses as told by the financial department of ZABTech (iTVET) Larkana Campus. Resultantly, it affects the financial position of the institute. In the early period of ZABTech (iTVE), the undergraduate programs were offered to make individual skilful in technology and support them in getting a job in any private sector or any industry. According to the statistical report of Sathar (2016), the population of Pakistan consists of $60 \%$ of youth, in which $78 \%$ boys and $67 \%$ girls get enrolled for school education lying under the age of 10-14 (Sathar, et al., 2016). The proportion declines for the age group of 20$24,76 \%$ of boys and $59 \%$ of girls enrolling for higher education belong to Sindh province (Shah \& Muhammad, 2017). Lack of education means no employment. In such conditions, technical and vocational institutes play a significant role in employment opportunities for Pakistan's youth. However, unfortunately, individuals were still unaware of the technical and vocational education and its benefits.

For improving the financial performance and rate of return, SZABIST-ZABTech (iTVE) took support from the government and other organizations such as European Union, GIZ (Deutsche Gesellschaft fur International Zusammenarbeit, Gmbh (German: German Society for International Cooperation, Ltd.) GIZ Gesundheits-InformationsZentrum) and OKFAM (Oxford Committee for Famine Relief). The TVET (Technical and Vocational Education and Training) was sponsored by the government and also stipend of 2,500PKR/Month paid to students. 
NBR

2,2

Page 53

Now several UNPO's (Unrepresented Nations and People Organizations) programs of the Provincial and federal government, and International programs are offered at ZABTech (iTVE) Larkana Campus, and that organization pays fees of students. Currently there are 13 batches enrolled in different In-source training programs, in which 12 different training programs are offered to the students free of cost as told by the management of ZABTech (iTVET) Larkana Campus. They have also introduced the awareness sessions for students to complete their required enrolled program which ultimately benefits their lifelong learning said by current principal. Resultantly institute has improved the financial return and sustainability. Presently, Larkana is a full-fledge financially sound institute and possesses several facilities such as infrastructure, vehicles, supporting staff, classes, and modern computer labs.

Hence, SZABIST_ZABTech (iTVE) is the most extensive training provider of technical and vocational education in the private sector at seven different campuses in Sindh province said by director in her interview. They have also worked with RDF (Research Development Foundation) in the region of Sangher and Khipro. Even a new project is being offered in ZABTech (iTVE) with SUCCESS (Sindh Union Council and Community Economic Strengthening Support) in which four new regions will be served which includes Dadu, Jamshoro, Kamber-Shadadkot, and Larkana. With the support of all these projects, ZABTech (iTVE) can be financially sound and plan for better future opportunities to bring change in the field of TVET education which could strengthen the youth of Pakistan and these individuals could compete globally.

\section{Conclusion}

Director has a strong vision for ZABTech (iTVE). The director and her team of Larkana campus struggled to overcome all these three main internal and external issues. Today, ZABTech (iTVE) is running its operations (SZABTech(iTVe), 2018) and focusing towards new opportunities to adapt change for the growth and sustainability of institute said by current principal. Director is looking forward to international recognition of ZABTech (iTVE) to produce a skilled workforce, focus on changing the infrastructure of the country through TVET (Technical and Vocational Education and Training).

She believes that in Pakistan, the infrastructure and quality of technical and vocational education are suffering. Being a visionary leader, she plans to improve the structure, at least in the private sector. As international degrees are costly and cannot be afforded by most of Pakistan's people, Director ZABTech wants to make them convenient and affordable for international accreditation students. However, unfortunately, ZABTech (iTVE) cannot individually afford the fees of being a private institute. So, she is looking forward for sponsors who pay the fees on behalf of students. ZABTech (iTVE) wants to produce a skilled workforce that can address the challenges of CPEC (China Pakistan Economic Corridor) and become a part of CPEC because an ample number of trained workforces is required. She is planning to establish a Pakistani training system to make the most of employment opportunities for youth in local and overseas job markets. With the help of TVET, she wants to change people's mindset besides bringing change in the country's infrastructure.

She aspires to change the perception of individuals towards the importance and significance of TVET education. There is a huge technological and skill-gap in Pakistan which can be filled by installing the TVET education in youth (Chamadia \& Shahid, 2018; Mahmood, 2003). In foreign countries, there is no difference between urban and rural areas in terms of infrastructure. 
NBR

2,2

Page 54

However, in Pakistan, much difference is observed. She believes that this gap would only be eliminated with the help of TVET. TVET education helps in selfdevelopment and economic development (Ansari \& Wu, 2013). It is highlighted in research that youth with technical and vocational education and skill confirm the economic and social development (Chamadia \& Shahid, 2018)

Our country cannot survive without privatization. The modern world is full of technology, we are surrounded by technology, and we need labour to repair and maintain that technology. We are just the end-users, and we cannot afford to hire foreign labour for the repair and maintenance so it is our compulsion to motivate our labour to acquire specific skills. ZABTech (iTVE) will provide the fund for further implementation of plans.

ZABTech (iTVE) works with different organizations, either private or public, like RDF (Research Development fund), IRC (Industrial Resource Center), Islaah foundation, and many others for project implementations for financial sustainability of institute and as well as to succeed in Technical and vocational education in Pakistan. Ms. Mahesar plans to establish a Pakistan training system to make the most of employment opportunities for youth in local and overseas job markets. Would it be possible for her to implement her plans in Pakistan and be successful?

\section{References}

Alumni, A. G. (2018). Strengthening Technical and Vocational Education Retrieved November 01, 2019, from https://www.australiaawardsafrica.org/ alumni_news/alumni-news-issue-25/

Ansari, B., \& Wu, X. (2013). Development of Pakistan's technical and vocational education and training (TVET): An analysis of skilling Pakistan reforms. Journal of Technical Education and Training, 5(2).

Butt, A., Lodhi, R. N., \& Shahzad, M. K. (2020). Staff retention: a factor of sustainable competitive advantage in the higher education sector of Pakistan. Studies in Higher Education, 45(8), 1584-1604.

Chamadia, S., \& Shahid, M. (2018). Skilling for the future: evaluating post-reform status of "skilling pakistan" and identifying success factors for TVET improvement in the region. Journal of Technical Education and Training, 10(1).

Clifford, M., Behrstock-Sherratt, E., \& Fetters, J. (2012). The Ripple Effect: A Synthesis of Research on Principal Influence to Inform Performance Evaluation Design. A Quality School Leadership Issue Brief. American Institutes for Research.

Kissi, E., Ahadzie, D. K., Debrah, C., \& Adjei-Kumi, T. (2020). Underlying strategies for improving entrepreneurial skills development of technical and vocational students in developing countries: using Ghana as a case study. Education+ Training.

Levin, J., \& Datnow, A. (2012). The principal role in data-driven decision making: Using case-study data to develop multi-mediator models of educational reform. School Effectiveness and School Improvement - SCH EFFECTIVENESS SCH IMPROV , 23, 179-201. doi: 10.1080/09243453.2011.599394

Mahmood, K. (2003). A comparison between needed competencies of academic librarians and LIS curricula in Pakistan. The electronic library.

Nooruddin, S. (2017). Technical and vocational education and training for economic growth in Pakistan. Journal of Education and Educational Development, 4(1), 130141. 
Nwachukwu, P. O., \& Yaba, L. (2014). Poverty reduction through technical and vocational education and training (TVET) in Nigeria. Developing Country Studies.(Paper) ISSN, 2225-0565.

Palmer, I., Dunford, R., \& Buchanan, D. A. (2017). Managing organizational change: A multiple perspectives approach: McGraw-Hill Education New York.

Sathar, Z., Kamran, I., Sadiq, M., \& Hussain, S. (2016). Youth in Pakistan: Priorities, Realities and Policy Responses. Population Council.

NBR

2,2

Page 55

Shah, S. A., \& Muhammad, N. (2017). Comparative analysis of TVET sector in Pakistan. Islamabad, Pakistan: National Vocational \& Technical Training Commission. Retrieved form: $\quad$ http://www.skillingpakistan.org/files/1/Comparative\% 20Analysis\% 20of\% 20TVET\% 20Sector\% 20in\% 20Pakistan. pdf.

Siyal. (2017-2018). annual Reort of ZABTech (iTVe) Larkana. Larkana: ZABTech(iTVe) Institute of Techical and Vocational education.

SZABTech(iTVe). (2018). Shaheed Zulfiqar Ali Bhutto Technology Institute of Technical and Vocational Education Retrieved November 01, 2018, from http://szabist-zabtech.edu.pk/

\section{About the Authors \\ Ms. Fatima Shaikh}

She is a PhD Scholar at Sukkur IBA University Sukkur, Pakistan. She did her MBA specialization in human resource management from SZABIST Larkana campus in 2013. She is a corporate Gold medallist in subject of Performance management. Her research interest includes Organizational Learning and knowledge management, Psychological Contract, Change Management, Human Resource Development and Human Resource Practices.

\section{Ms. Murk Memon}

She is a PhD Scholar at Sukkur IBA University Sukkur, Pakistan. She did her MBA specialization in human resource management from SZABIST Islamabad campus in 2012. Her research interest includes Organizational Learning and knowledge management, Psychological Contract justices and Change Management.

\section{Dr. Manzoor Ali Mirani}

Dr. Mirani graduated with a PhD in Management from University Tun Abdul Razak Malaysia. Dr. Mirani has rich boardroom experience of serving on Board of Governors Sukkur IBA, and Senate of Sukkur IBA, Academic Council of Sukkur IBA University. Currently he is a head of department of business management science. He is also a member of Board of Studies, Institute of Commerce University of Sindh Jamshoro, and Department of Public Administration Shah Abdul Latif University Khairpur, and Department of Management Sciences \& Technology, BNB Women University Sukkur. Research Areas: Entrepreneurship, Academic Entrepreneurship, Entrepreneurial Universities, Strategic Management, HR Practices.

\section{Dr. Gul Afshan}

Gul Afshan is an Assistant Professor at Sukkur IBA University, in Pakistan. She has completed her PhD from IAE-Aix Marseille Graduate School of Management, France. Her research interest includes leader-member exchange, supervisory justice, and supervisor support, conflict at workplace, CSR and knowledge management.

The Corresponding Author Fatima Shaikh can be contacted at: Fatima.phdmgt17@iba-suk.edu.pk 
NBR

2,2

Page 56

\section{DISCLAIMER:}

Names of principals have been disguised to maintain ethical consideration.

List of supplementary materials (must include teaching notes)

1- Cooperrider, D. L., E Whitney, D. (2001). A Positive Revolution in Change: Appreciative Inquiry. 36.

2- Palmer, I., Dunford, R., E Buchanan, D. A. (2014). Managing Organizational Change. United States of America: Mc Graw Hill Education.

3- Wolf, D., E Hanson, B. (2017). The resilience of appreciative inquiry allies: business education sustains the business community. International Journal of Human Resources Development and Management, 48-56.

EXHIBIT: 1AUSTRALIAN GLOBAL ALUMNI
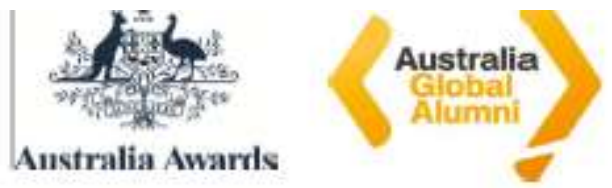

\section{Profile: Waheeda Mahesar}

\section{Strengthening Technical \& Vocational Education in Pakistan}

Through an Australia Awards Short Course, waheeda developed her understanding of industry engagement models as well as gender equality in vocational education and training - vital to her work in Pakistan.

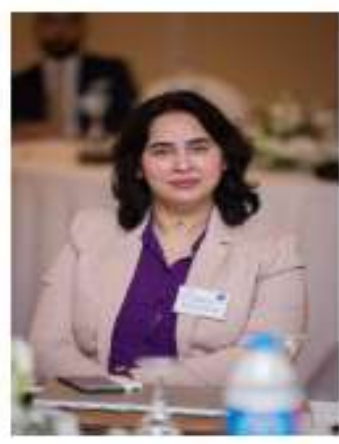

Above: Waheeda Hahesar, Austraila Awaros ailuma
Waheeda Mahesar is Director of the Shaheed Zulfiqar Ali Bhutto Institute of Science and Technology (SZABIST) ZABTech Institute of Technical \& Vocational Education (ITVE), the largest TVET provider in Sindh, Pakistan.

She holds a Masters in Computer Science and Public Administration and has experience working in various positions in the development sector as well as in academia.

In 2015, Waheeda was awarded a three-week Australia Awards Scholarship to attend a Short Course in "Supporting the Strengthening of Technical and Vocational Education and Training; Policy and Management' at the Queensland University of Technology in Brisbane.

"It was my dream to be a part of Australia Awards, to obtain a new qualification and leam in Australia's beautiful cities like Brisbane and Canberra," she says.

Waheeda found the Short Course to be very relevant to her job as Director of SZABIST ZABTech (iTVE). Furthermore, the course was aligned with the Pakistan National Skills Strategy. which aims to create a paradigm shift from a supply-based system to demand-driven models through the collaborative efforts of training providers, the industry and employers.

The Short Course gave her an understanding of industry engagement models, stakeholder engagement, community programs related to training and employment, as well as gender equality in vocational education and training

It also provided her with a broader perspective on developing policies to support and strengthen human resources in the TVET sector. This helped her draw on what she learnt from the Australian TVET systems, to benefit SZABIST ZABTech.

"Taking part in Australia Awards was an excellent academic leaming opportunity and a wonderful and memorable experience," she says.

During her Short Course she had the opporturity to visit a number of businesses and training providers, including TAFE Queensland SkillsTech, Hutchinson Builders, the Gold Coast School of Construction, the Motor Trade Association Institute of Technology and the Australian Skills Quality Authnrity (A.SกA) 
Waheeda has dnwin on learnings from her short course by

introducing institute Management

NBR

Committees at SZABBST ZAETech.

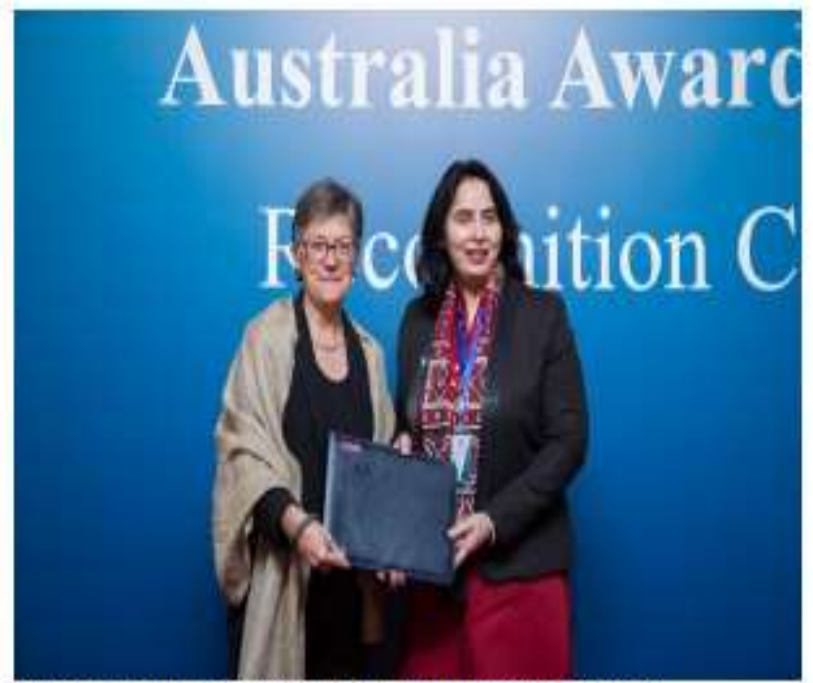

Above: Austallan High Commissibner to Pakistan, Nos Margaret Adamson

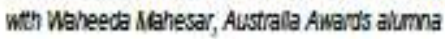

She has drawn on learnings from her Short Course by introducing Institute Management Committees (IMC) at SZABIST ZABTech where employers are given a leading role.

Since her retum to Pakistan, Waheeda has been nominated by The Deutsche Geselischaft für Intemationale Zusammenarbeit (GIZ) as a member of the Provincial Advisory Forum for the TVET sector, representing the private sector.

In the future, she plans to establish a demand-driven training system in Pakistan to make the most of employment opportunities for youth in local and overseas job mankets. She also intends to pursue a PhD in TVET systems.

Australia Awards are prestigious intemational Scholarships, Fellowships and Short Courses funded by the Australian Govemment. Australia Awards Short Courses offer the next generation of global leaders an opportunity to undertake short-term study, research and professional development opportunities in support of key development and foreign affairs prorities. 


\section{EXHIBIT:2 PROFILE OF DIRECTOR ZABTECH (ITVE)}

\section{DIRECTOR}

Phone Off: 021-35220217-8

Email: https://szabist-zabtech.edu.pk

NBR

2,2

WAHEEDA MAHESAR

Directorate of SZABIST-ZABTech (iTVE)

Ground Floor, Sheikh Sultan Trust,

Building No. 1, Beaumont Road, Karachi-75530

Professional Summary

I am working as a director, at SZABIST-ZABTech, Shaheed Zulfikar Ali Bhutto, Institute of Science \& Technology, Sindh Pakistan. SZABIST-ZABTech is a prime vocational training institute in Sindh. My fields of expertise are Institutional Development, Project Planning \& Management, Training \& Curriculum Development, and Monitoring \& Evaluation of activities \& Report Writing. At ZABTech, we are creating opportunities for the underprivileged communities and deserved youth through imparting skills training. I started my career as a Research Associate at the University of Sindh Jamshoro \& then joined SZABIST University as Faculty Computer Sciences. In 2014 I have been promoted to the position of Director, SZABIST - ZABTech (iTVE) that has been established after the achievements of the Job Skill Training Centers. Now since 2014, I have been working as a Director of SZABIST-ZABTech (iTVE).

I hold a dual Master's degree in Public Administration \& Computer Sciences \& now doing an M.Phil thesis. I have travelled to different International Institutions \& Universities where participated in different TVET related programs and conferences. During my professional career, I have visited national and international forums and gained cross-cultural experiences. These cross-cultural exchanges are a great source of my inspiration and have played a significant role in MY professional and intellectual life.

During my professional career, I visited many countries and actively participating in different socio-economic and cultural forums at regional, national, and international level. I am actively participating in the Women Action Forum, Sindh Social Scientists Forum \& other right based forums/organizations. I am also contributing as director of different boards/committees of civil society organizations and continuously giving my input for the betterment of society. 
